\title{
Metodologia Lean no Pronto Socorro de um Hospital Público do Município de Guarulhos.
}

\author{
Eixo temático: Gestão em Saúde
}

\section{INTRODUÇÃO}

Com a alta da demanda e o aumento dos custos hospitalares a questão de superlotação nos Prontos Socorros está em foco. No intuito de tornar o atendimento mais eficiente foi aplicada a metodologia Lean Healthcare que é uma filosofia de melhoria de processos de trabalho baseada em tempo e valor.

\section{OBJETIVO}

Descrever a implantação da metodologia e demonstrar os resultados com relação ao tempo de atendimento.

\section{MÉTODO}

Estudo de caso em um serviço de emergência de um hospital público de grande porte, após três meses de implantação da metodologia, com apoio do Programa de Desenvolvimento Institucional do Sistema Único de Saúde. A amostra foi constituída de dados numéricos relacionados a tempo antes e depois da intervenção, que foram coletados e organizados em planilha excel. Observados fluxos de trabalho, desenhada a cadeia de valor do atendimento e identificadas as oportunidades de melhoria. Realizadas as etapas de implantação do 5'S - sensos de organização, limpeza, utilização, padronização e autodisciplina, mapeamento de fluxo de valor descrito, brainstorming e aplicação do $5 \mathrm{~W} 2 \mathrm{H}$, todas as etapas realizadas pela equipe operacional. Definiu-se por pacientes verticais e horizontais de acordo com o tipo de entrada. $\mathrm{Na}$ descrição dos resultados foi utilizado o LOS - tempo de passagem do paciente com e sem internação e a taxa de agregação de valor.

\section{RESULTADOS}

Taxa de agregação de valor para pacientes horizontais foi de $1 \%$ para $14 \%$ com um incremento de $13 \%$. Já com os pacientes verticais a mesma taxa foi de $15 \%$ a $31 \%$ com incremento de $16 \%$. O LOS dos pacientes com internação foi de 3129 minutos para 1341 minutos e o sem internação passou a 180 para 32 minutos.

\section{CONCLUSÃO}

A implantação permitiu a reavaliação das práticas levando a organização dos setores de maneira mais racional, fluxos adequados e melhores resultados dos tempos de atendimento em apenas 5 (cinco) meses.

\section{REFERÊNCIAS BIBLIOGRÁFICAS}
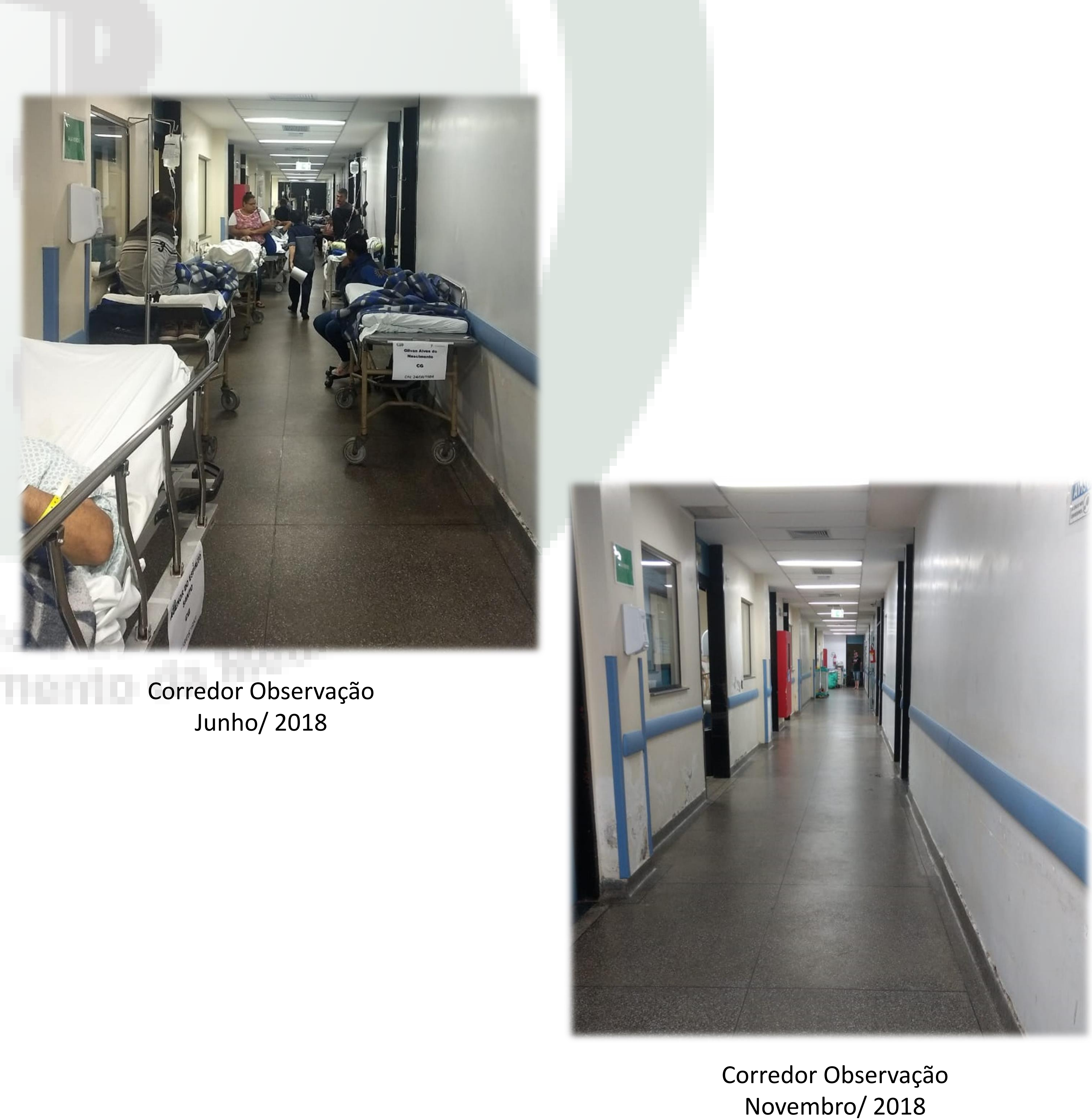

Hadfield D, Holmes S, Kozlowski S, Sper Todd. O Lean na Área da Saúde: Ferramentas para a eliminação do desperdício em hospitais, clínicas e outras instituições de saúde. 1a ed. Rio de Janeiro: DOC Content, 2016. Lapão L.V. Lean na Gestão da Saúde: Uma oportunidade para fomentar a centralidade do doente, o respeito pelos profissionais e a qualidade nos serviços de saúde. Acta Med Port 2016 Apr;29 (4): 237-239. 